\title{
Treatment of Olive-Mills effluent using Electro-osmosis Dewatering
}

\author{
Sameer Al-Asheh*, Rami Juma, Fawzi Banat, Amani Al-Zou'bi and Nesreen Al-Qutaish
}

Department of Chemical Engineering, Jordan University of Science and Technology, P.O.Box 3030, Irbid 22110 Jordan

\begin{abstract}
Direct current is applied to olive mill wastewater effluent which is held between two electrodes in a vertical mode. Wastewater with a total dissolved solid and COD of about 39,300 and 120,000 mg/l, respectively, is used. The effect of $\mathrm{pH}$, voltage, current, and bed height on the dewatering process is investigated. The results, under certain conditions, showed that EOD is an energy saving process for water removal and can be used for treatment of olive mill wastewater. The process revealed high efficiency in reducing COD and total dissolved solid (TDS). Water medium converted from acidic to basic upon application of direct current. Increasing the voltage or the current enhanced the EOD process. Use of additives at certain level also enhanced the dewatering process; addition of alum or electrolyte at certain concentration enhanced the removal rate. Sodium chloride is the most effective electrolyte in EOD process. The on/off test, although saves energy, but did not perform better in the term of percentage water removal compared to that of the continuous process, without on/off test.
\end{abstract}

Keywords: Olive mill wastewater; EOD; Direct current; COD; TDS

\section{Introduction}

Wastewater produced from olive oil processing constitutes a major environmental impact and a problem which cannot be easily solved by the specific agricultural industrial sector. This is due to the high non-biodegradable organic content of such waste. The toxicity of this type of wastewater is due to the high concentrations of polyphenolic compounds. Typical olive mill wastewater is characterized by very high chemical oxygen demand, COD (40-200 g/l), biological oxygen demand, BOD (12-60 g/l), total solid content (40-150 g/l) and acidic $\mathrm{pH}$ (about 5). The uncontrolled disposal of olive oil mill effluent leads to intense phytotoxic phenomena in flora, quality degradation of ground water reservoirs, surface aquatic reservoirs, and seashores and sea. Furthermore, evaporation from the wastewater lagoons may lead to unpleasant odors and increase of the insect population in those areas, which is inconvenient to the nearby living inhabitants.

Various treatment technologies are available for treatment of OMW. For example, Hayek et al. [1] used the up flow anaerobic sludge blanket (UASB) reactor for the treatment of the olive mill wastewater. They used two different laboratory scale reactors of 3-liter and 15-liter size. They found that COD reduction efficiency reached $75 \%$ in both cases and the biogas production was $79.6 \%$ of methane. Boari et al. [2] used a lysimeter in a pilot scale to simulate a cell of a sanitary landfill. They claimed that the landfill could act as anaerobic filter and reduced the pollution load of the OMW while acting as a temporary storage tank. Their results showed that the COD reduction efficiency was $70 \%$. Electro-osmotic dewatering is an energy saving water removal process and can be used for treatment of olive mill wastewater. Electroosmosis dewatering (EOD) is a technique that removes water by placing a colloidal material between two electrodes. This is based on the electrostatic effects of the electrochemical double layer that is formed at the particle water interface of the colloidal material. The polarization of water molecules near the solid-liquid interface causes an electrical double layer to form [3]. In this double layer, the charges on the surface of the particles are electrically balanced by the opposite charges in water, when an electric field is applied across the medium, the electric double layer causes the motion of the particles (electrophoresis) and the liquid (electro-osmosis); electrochemical reactions at the electrodes occurred based on the electrolysis of water in the bed. Electro-osmosis dewatering has been studied for its proven advantages [4] in term of high efficiency, low energy consumption and being free from blockage of the filter media by sludge particles at high concentration as occurred in filtration (mechanical dewatering). It has been proven that the energy saving by EOD is about $75 \%$ compared with vaporization of water [4]. The technique has been used for concentration of food materials [5-8], activated sludge [9-11], contaminated sediment [12] and organic soil [13].

Effects of different parameters on the EOD process have been significantly considered in literature. For example, Lockhart [14] has studies the effects of different factors on the electro-osmosis dewatering of sodium kaolinite suspension. The author started with a constant voltage and then increased the input voltage to improve the process. His study showed that the addition of $\mathrm{NaCl}$ salt or $\mathrm{HCl}$ acid decrease the voltage needed to remove higher percent of water at the same voltage. Also he concluded that there was no relation between water flux per unit charge, from one side, and ion concentration and zeta potential from other side. Ju et al. [15] have studied the electroosmosis dewatering of bentonite under constant voltage and DC (Direct Current). They determined the effects of initial solid content, initial bed height, constant applied voltage, constant applied current and the concentration of added $\mathrm{CaCl}_{2}$ on the EOD of bentonite. They found that $60 \%$ of water can be removed by electro-osmosis, and the required energy was less than that required to the vaporization water. It was concluded that as the bed height decreases the energy of dewatering decreases and the water flux per unit charge increases. Rabi [16] has investigated EOD of bentonite suspensions under continuous and interrupted DC voltage and current. Yoshida et al. [17] have examined the electro-osmosis dewatering of activated sludge under AC electric field with periodic reversal of electrode polarity. The authors found

*Corresponding author: Sameer Al-Asheh, Department of Chemical Engineering Jordan University of Science and Technology, P.O.Box 3030, Irbid 22110 Jordan, E-mail: alasheh@just.edu.jo

Received March 03, 2011; Accepted May 19, 2011; Published May 28, 2011

Citation: Al-Asheh S, Juma R, Banat F, Al-Zou'bi A, Al-Qutaish N (2011) Treatment of Olive-Mills effluent using Electro-osmosis Dewatering. Hydrol Current Res 2:113. doi:10.4172/2157-7587.1000113

Copyright: @ 2011 Al-Asheh S, et al. This is an open-access article distributed under the terms of the Creative Commons Attribution License, which permits unrestricted use, distribution, and reproduction in any medium, provided the original author and source are credited. 
that the application of AC (alternate current) electric field resulted in a decrease of electrical resistance and that the final amount of removed water was higher than that under DC electric field. Chen et al. [18] has dewatered vegetable waste electro-osmotically starting with high moisture content. They found that there is proportionality between bed height and percent of water removal and that as $\mathrm{pH}$ goes to neutral value the percent of water removal increases and vice versa. Zhou et al. [19] has worked on a new method to remove water from a sludge using a horizontal electric field in order to facilitate the runway gases produced at the electrodes and to keep the anode immersed in water during the dewatering process. The authors compared their method to those operated in a vertical electric field, and concluded that the method described in their study has high efficiency, simple structure and ease of operation. An attempt has also been made by Tezcan et al. [20] to remove COD using poly aluminum chloride, as coagulantaid, by an electrochemical method using either iron or aluminum as sacrificial electrode. The apparatus constructed by those authors was very simple one and the parameters considered were limited. They have employed cylindrical container in which the suspension is added and continually mixed with a stirrer; while one pole of the power supply was connecting to the reactor operating as a cathode, the other was connected to a stirrer as an anode. Recently Iwata et al. [21] studied enhancement of dewatering process by analysis of combined electroosmosis dewatering and mechanical expression operation. Another recent investigation by Hsu et al. [22] considered the unified analysis of dewatering and drying of sludge cake. The constant voltage and constant current electro-osmosis, combined with vacuum filtration were adopted to dewater the fine coal [23]. Curvers et al. [24] studied the influence of ionic strength and osmotic pressure on the dewatering behavior of sewage sludge; they found that an increase in the bulk ionic strength brings about an increase in the final solid volume fraction upon constant pressure filtration or centrifugation. An advanced study was considered by Yang et al. [25] who investigated the structure evolution of wastewater sludge during electro-osmosis dewatering by means of Pore size distribution (PSD), box-counting fractal dimension, and volume change of sludge matrix.

Although free disposal of OMW into the environment is not permitted by law, the wastewater from different olive mills located in different areas of Jordan is being disposed into the valleys, affecting the soil, groundwater and water courses downstream. Therefore, OMW must be treated before being discharged into receiving water bodies or being used for irrigation purposes. In this work, the possibility of treating OMW by electro-osmosis dewatering (EOD) process is considered using bench-scale experimental apparatus designed for such purpose. Specific objectives include study of the effect of voltage, current, and bed height on the dewatering process; explore the effectiveness of the EOD by estimating water flux per unit charge and energy of dewatering per mole of water removed; study the effect of EOD on the degradation of chemical oxygen demand (COD) of the olive mill wastewater; and investigate the effect of adding coagulant and electrolyte on the EOD performance. The effect of ionic strength and intermittent operation to save energy are also considered.

\section{Materials and Methods}

\section{Experimental apparatus}

Electro-osmosis dewatering apparatus has been constructed in this work. A schematic diagram of the apparatus is shown in Figure 1. This is a bit different than the set up employed by Tezcan et al. [20]. The apparatus consists of a cylinder fitted with two electrodes. The cylinder is used to contain the sample of wastewater. The two electrodes are disks made of stainless steel; the diameter of the disk was $8 \mathrm{~cm}$. Each disk contains 174 holes arranged in diamond manner; the diameter of the hole was $3 \mathrm{~mm}$. Wires are fixed to both of the electrodes using epoxy glue and are connected to a D.C. power supply. There are holes drilled on the bottom electrode to provide drainage of both water and gases produced by electrolysis. A filter cloth is placed on top of the disk to prevent the colloidal material from clogging the holes. A plate is placed underneath the lower electrode to collect the water drained from the sample. This plate is connected to a gradual cylinder to measure the volume of the water removed during the experiment. The other electrode is connected to a piston, which has a mass of $556 \mathrm{~g}$, and placed on the top of cylinder. When pressure is applied, which is just the weight of the piston and the atmosphere (i.e. $102.41 \mathrm{kPa}$ ), the upper electrode presses the tailing bed in the cylinder and closes the electric circuit for electroosmosis. The electrodes are chosen to be anode (+ve) on the top and cathode (-ve) on the bottom, due to zeta potential [26]. The experiments have been carried out at room temperature. Detailed description of the apparatus and experimental procedure are provided elsewhere [6,7].

\section{Materials and analysis}

A sample of olive oil mill wastewater was obtained from certain olive oil processing plant in the northern area of Jordan. Olive mill effluent wastewater was collected during the olive harvesting seasons (October-January 2008). The sample of wastewater was collected in metal container, which was kept closed and preserved at low temperature.

The following variables were measured experimentally using certain analytical procedure: $\mathrm{pH}$, total solid content (TS), and chemical oxygen demand COD.

pH: A digital calibrated $\mathrm{pH}$ meter made by WPA (Wissenschaftlich Technische Werkstatten, Germany) was used to measure the $\mathrm{pH}$ of the olive mill effluent wastewater samples.

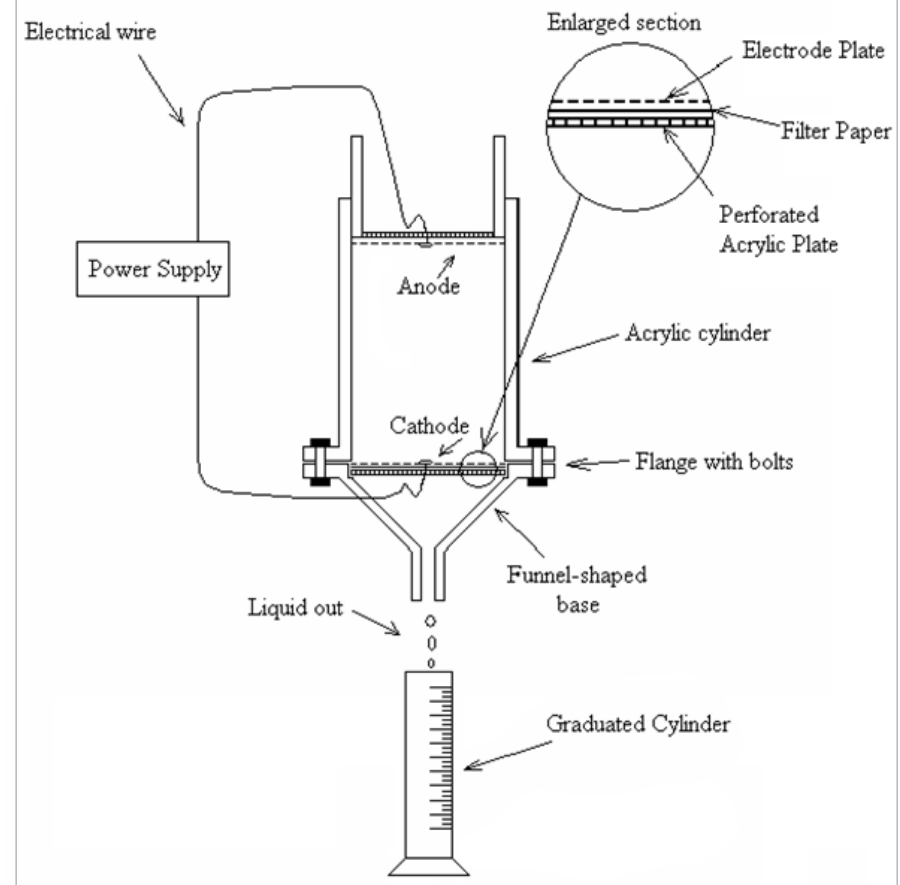

Figure 1: Electroosmosis dewatering apparatus 
TDS and COD: TDS and COD were measured following the APHA methods [27].

Each experiment was carried out in duplicate and the average results are presented in this work if they did not differ by more than $7 \%$. Blank experiment was conducted without applying electromotive forces; it was noticed that almost no water passed through the electrodes without applied voltage.

\section{Effect of various parameters on EOD operation}

Effect of voltage: Tests have been conducted to study the effect of voltage on the electro-osmosis of OMW. At certain voltage (10 or 15 or $20 \mathrm{~V}$ ), a suspension of $200 \mathrm{ml}$ was prepared and maintained at fixed height of the bed $(3.1 \mathrm{~cm})$.

Effect of current: The effect of current variation on the EOD of OMW has been investigated. In this case, the bed height was maintained at $3 \mathrm{~cm}$ and EOD was conducted using three different currents, namely $0.1,0.25$ and $0.5 \mathrm{~A}$ and EOD were followed.

Effect of bed height on the EOD of OMW: Initial bed height is one of the most important variables in EOD technology. Its effect on OMW treatment is studies using two bed heights, namely 2.0 and $4.0 \mathrm{~cm}$. The initial solid concentration and electrical voltage were fixed at $4.4 \mathrm{wt} \%$ and $20 \mathrm{~V}$, respectively.

\section{Results and Discussion}

\section{Effect of voltage on EOD of OMW}

The results are shown in Figure 2A, B and C for rate of water removal, current variation and energy of dewatering, respectively, at each of the above-mentioned applied voltage. The rate of water removal was almost constant during the first stage of the process, and started increasing after $30 \mathrm{~min}$. These results also showed that an increase in applied voltage resulted in an increase in the dewatering rate. It should be noted that the effective force on the dewatering process was the electrical potential only; neither external pressure nor bed height were varied during the EOD process of this work. This effective force is governed basically by Ohm's law $(V=I R)$. The potential direction of the power was constant form the upper electrode (anode) to the lower one (cathode), thus the solid particles were attracted to the anode while the water decreased at the portion closer to the cathode where the water content is high and higher driving force for the water molecules. The dewatering rate ceased when the electrical resistance attained its maximum value and the effect of electrical field was minimum. A similar trend was reported in literature for EOD using other types of suspension [28].

It is also seen (Figure 2B) that the current is decreasing, indicating an increase in the resistance while dewatering process taking place. The instantaneous energy of dewatering is expected to decrease with percentage removal (Figure 2C), which is due to the decrease in the electrical current, since $\mathrm{E}=\mathrm{I}^{2} \mathrm{R}$. This is achieved at a voltage of $20 \mathrm{~V}$, but this is not the case at the beginning of the dewatering process for the applied voltages of 10 and $15 \mathrm{~V}$. The removal rate at the start up of these experiments is maintained zero, thus the process need a lot of energy to start dewatering process; when water is collected, the energy of dewatering decreased with time, although the accumulative energy of dewatering is increased with time. A similar conclusion was obtained for electro-osmotic dewatering of tofu residue (okara) [5].

Characteristics of the wastewater before and after EOD treatment are summarized in Table 1. The original wastewater is acidic with high content of COD which is due to highly organic matters including nitrogen compounds, sugars, organic acids and phenols which increase their organic loads. The TDS is also very high $(39300 \mathrm{mg} / \mathrm{L})$ in the original solution, but is significantly reduced upon EOD treatment. The $\mathrm{pH}$ increases to an about 10.4 , this could be due to the degradation of phenolic compounds upon EOD treatment. It is seen (Table 1) that COD and TDS have been reduced to $56.6 \%$ and $76.5 \%$, respectively, by this filtration technique. The high reduction in TDS of the solution indicates that the solid material is retained on the electrodes through the process.

\section{Effect of current on EOD of OMW}

The collected data are presented in the Figure 3 and Table 2. In
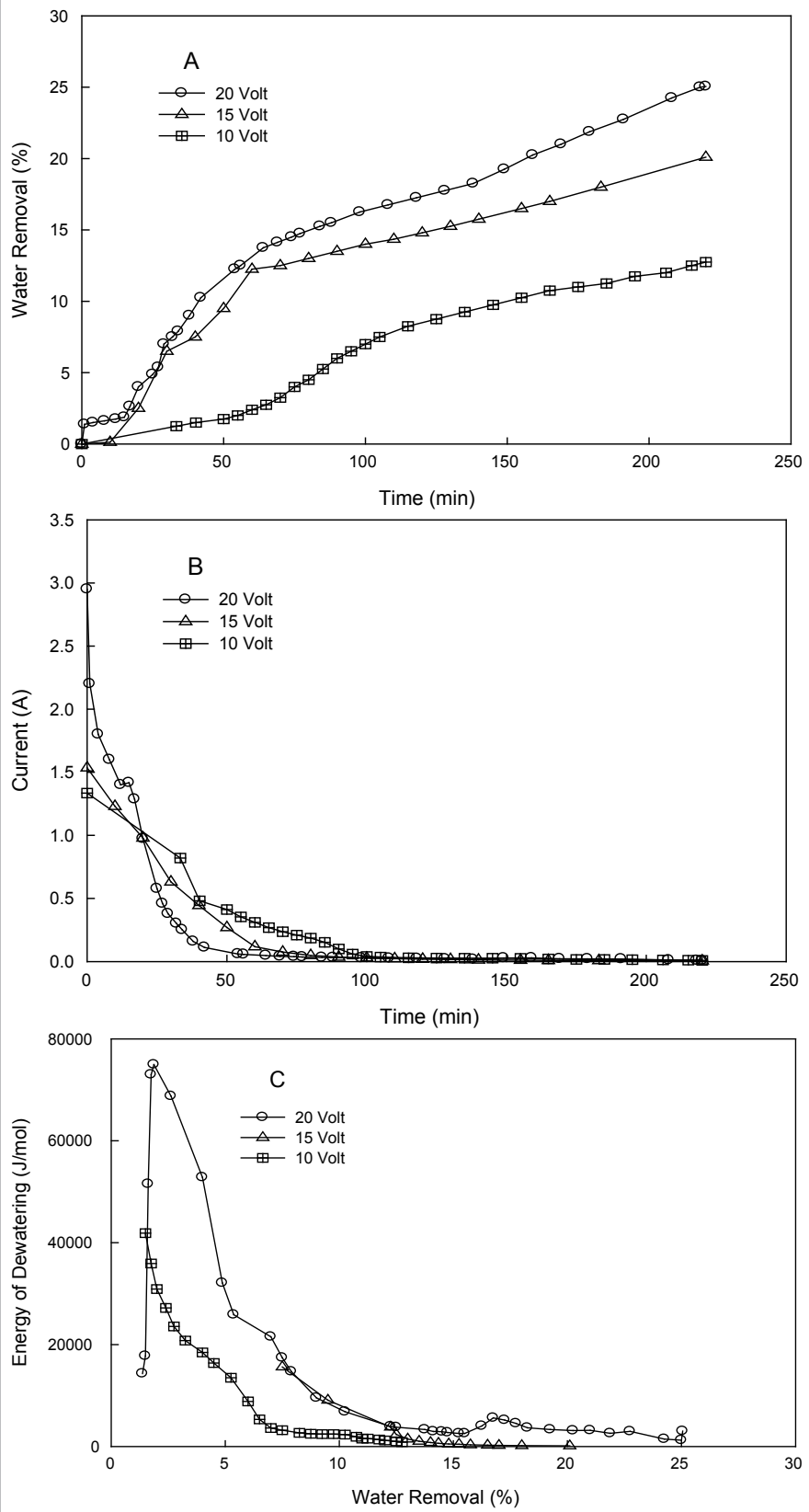

Figure 2: Rate of water removal $(A)$, current variation $(B)$ and energy of dewatering $(\mathrm{C})$ for during dewatering of OMW at different applied voltages and bed height of $3.1 \mathrm{~cm}$. 
general, the percentage removal increases with time [8,29-31]. It is expected that as the current increases the percentage removal increases, at any given period of time (Figure 3A). Following the dynamics of the experiment, this is true only at the end of experiments. Figure 3B shows that as the current increases the voltage increases for a given period of time. This is due to the random generation of gas in the upper electrode

\begin{tabular}{|l|l|l|l|}
\hline Voltage $(\mathrm{V})$ & $\mathrm{COD}(\mathrm{mg} / \mathrm{L})$ & TDS $(\mathrm{mg} / \mathrm{l})$ & $\mathrm{pH}$ \\
\hline Original & 120000 & 39300 & 4.525 \\
\hline 10 & 55100 & 9486 & 9.237 \\
\hline 15 & 54700 & 9238 & 11.392 \\
\hline 20 & 46500 & 8990 & 10.432 \\
\hline
\end{tabular}

Table 1: Characteristics of OMW after EOD process under constant voltage.
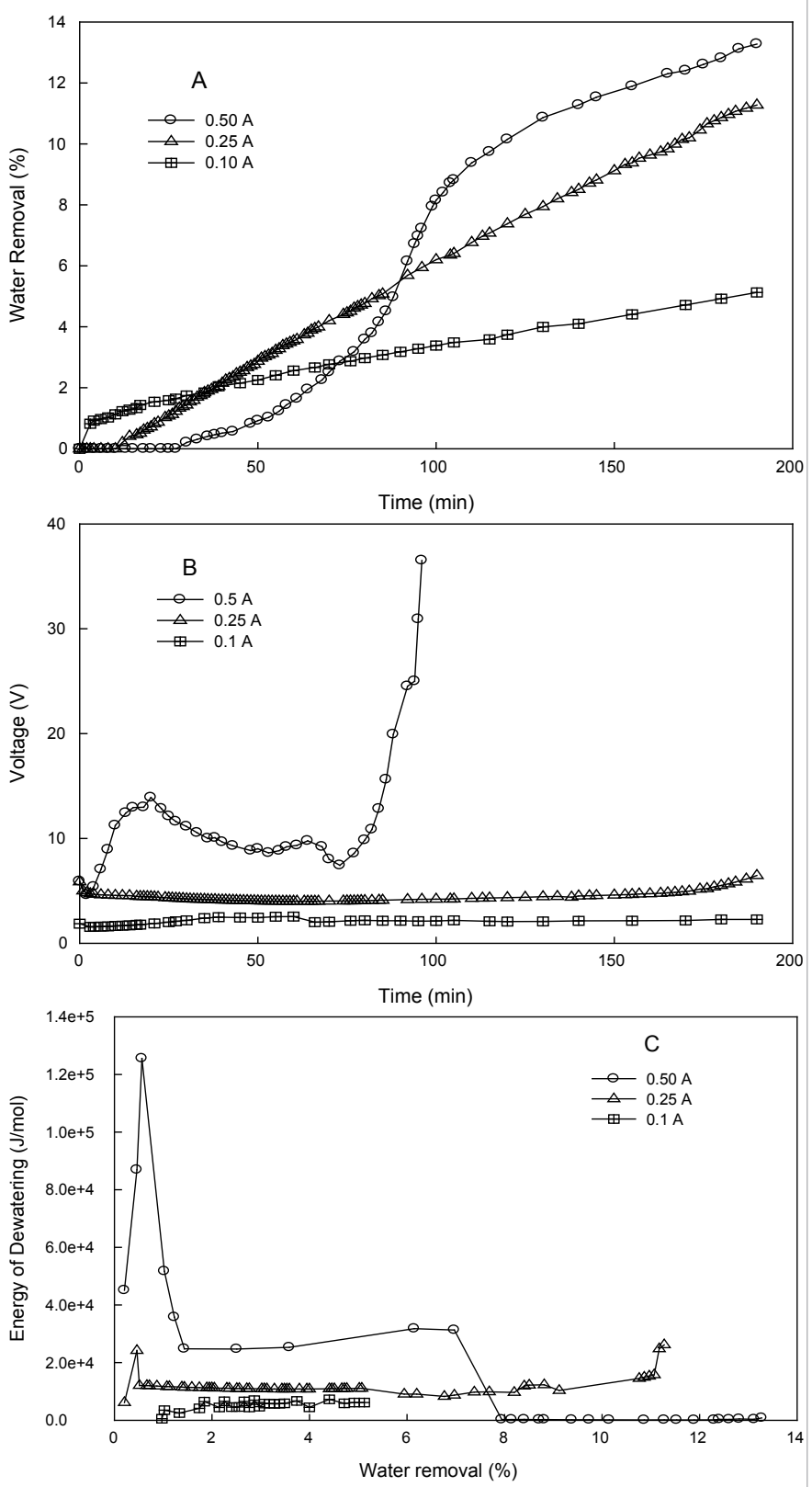

Figure 3: Percentage of water removal $(A)$, voltage variation $(B)$ and energy of dewatering (C)for OMW using constant DC current, bed height of $3 \mathrm{~cm}$, and $20 \mathrm{~V}$ voltage.

\begin{tabular}{|l|l|l|}
\hline Current $(\mathrm{A})$ & COD $(\mathrm{mg} / \mathrm{L})$ & TDS $(\mathrm{mg} / \mathrm{l})$ \\
\hline Original & 120000 & 39300 \\
\hline 0.1 & 42800 & 16740 \\
\hline 0.25 & 33600 & 13950 \\
\hline 0.5 & 32000 & 10825 \\
\hline
\end{tabular}

Table 2: Characteristics of water after EOD process under constant current.

which changes the resistivity of the bed and the degree of electrical contact of the suspension and the upper electrode. According to these results, the voltage increases with time until a maximum value $(37 \mathrm{~V})$ is reached and remained constant. This is due to limitation of the power supply used in the measurement, which can stand up to $37 \mathrm{~V}$. Thus, at this point the current began to decrease at the range of (0.2-0.09 $\mathrm{A})$, although the value of current was fixed. Figure $3 \mathrm{C}$ shows that the energy of dewatering decreases with time. This is for the same reason explained above. The reduction in COD and TDS increases with the increase in the applied current, i.e. about $73 \%$ the COD and TDS in original sample has been reduced when the current was 0.5 A (Table 2). Al-Asheh et al. [8] studied the effect of current during electroosmosis dewatering of tomato paste suspension. They also found that the increase in applied current resulted in an increase in the rate of dewatering.

\section{Effect of bed height on the EOD of OMW}

As expected, the rate of water removal is lower at higher bed height than that at the higher one (Figure 4A). This could be due to the low electrical resistance at low levels of the bed, which causes a greater effect of the electrical field. The amount of suspension in a $4 \mathrm{~cm}$ bed height is greater than that in a $2 \mathrm{~cm}$ bed height. Thus, although the percentage of water removed at higher bed height was greater than that at lower bed height. Looking at the current variation, it is seen (Figure 4B) that the current decreases sharper when using 2-cm bed height than that of $4-\mathrm{cm}$ bed height, which due to the same reason. Variation in energy of dewatering (Figure 4C) are only occurred only at low water removal for the two bed height; while it is the same for water removal greater than $4 \%$. Results for the COD, TDS and $\mathrm{pH}$ at the two bed height are shown in Table 3. These measurement were taken for the finally collected samples. It is seen that reduction in COD and TDS is higher at $2-\mathrm{cm}$ bed height than that at $4-\mathrm{cm}$ bed height, while the $\mathrm{pH}$ is almost constant.

\section{On/off test}

This test was conducted in order to study the possibility of saving energy by turning the apparatus on for certain period of time and then turning it off for another period of time. This was performed over a period of $6 \mathrm{hrs}$. The results are presented in Figure 5 and Table 4 . The percentage removal of water is increasing with time, however, the case of continues power supply, without on/off test, performs better than the two scenarios of the on/off tests shown in Figure 5. This is due to the effect of power on the dewatering process; since as power increases the removal rate increases, and thus the initial amount of suspension in an on and off process is greater than that in the continuous process. This is also supported by the results displayed in Table 4 . In general, the current was decreasing with time, and also was decreasing with the increase in the power consumption. The instantenuous energy of dewatering was found to bethe lowest when using continuous power supply; but largest value of the accumulative energy of dewatering was noticed in the cases of 20 on and 10 off and 10 on and 20 off. This is due to repeating the start up process in the experiment, as the start up requires significant amount of energy. 


\section{Effect of addition of coagulant}

Electrocoagulation of olive mill wastewaters has been previously investigated by other workers [20]. They found that the removal efficiency of COD was increasing with the addition of coagulant and that $\mathrm{Fe}$ was more effective than $\mathrm{Al}$ as an electrode. In this work, effect of coagulant has been studied in order to see if it is possible to enhance the dewatering process by this treatment. In this series of experiments a solution of alum prepared in a concentration of $0.3 \mathrm{wt} \%$ and was added
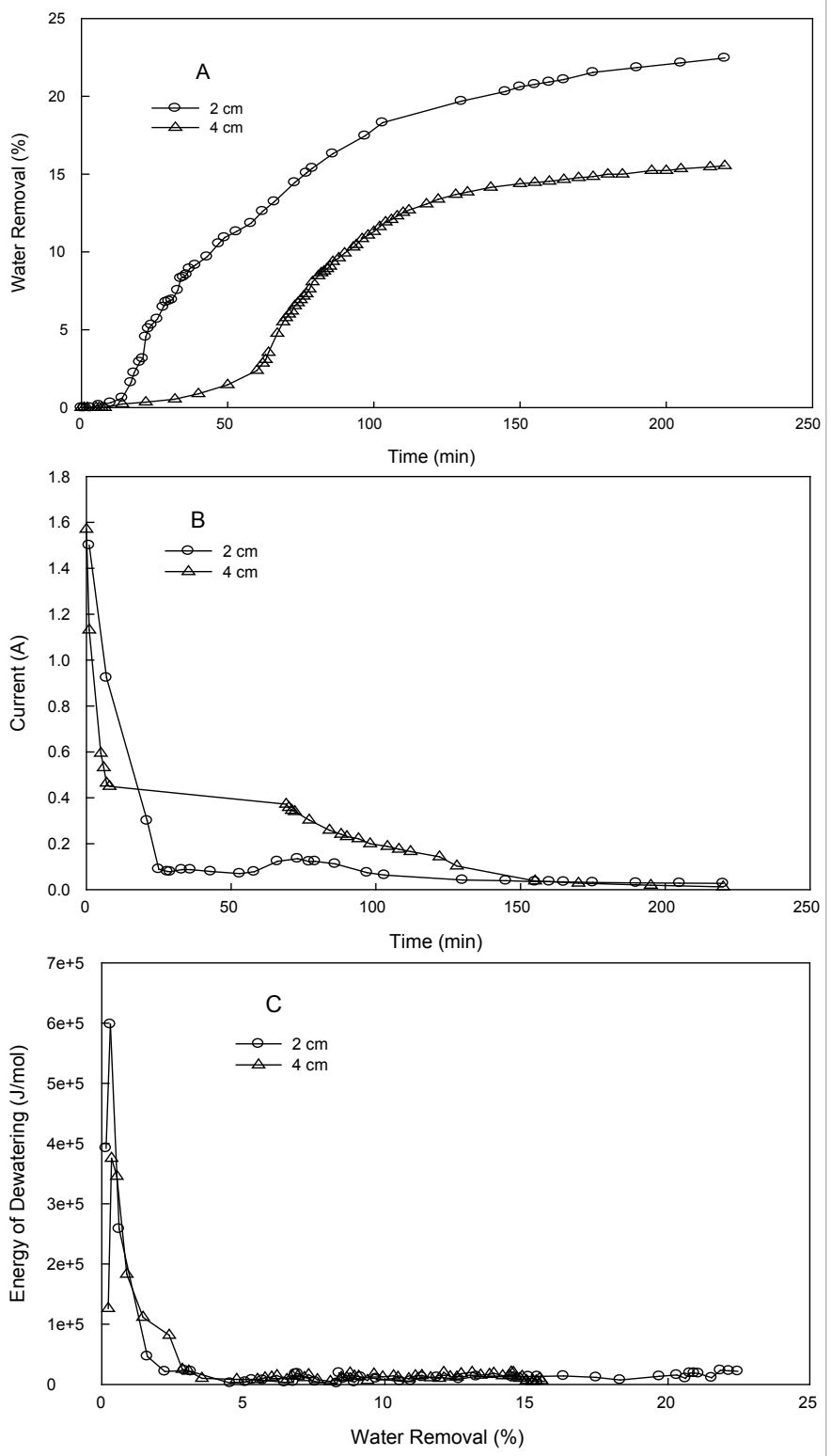

Figure 4: Percentage of water removval $(A)$, current variation $(B)$, and energy of dewatering $(\mathrm{C})$ for OMW at different bed heights under constant DC voltage, initial solid concent. $4.4 \mathrm{wt} \%$, voltage $20 \mathrm{~V}$.

\begin{tabular}{|l|l|l|l|}
\hline Bed height & $\mathrm{pH}$ & TDS $(\mathrm{mg} / \mathrm{l})$ & $\mathrm{COD}(\mathrm{mg} / \mathrm{l})$ \\
\hline Original & 4.525 & 39300 & 120000 \\
\hline $2 \mathrm{~cm}$ & 7.57 & 8680 & 37900 \\
\hline $4 \mathrm{~cm}$ & 7.71 & 9300 & 46000 \\
\hline
\end{tabular}

Table 3: Characteristics of water after EOD process under constant voltage and various bed heights.

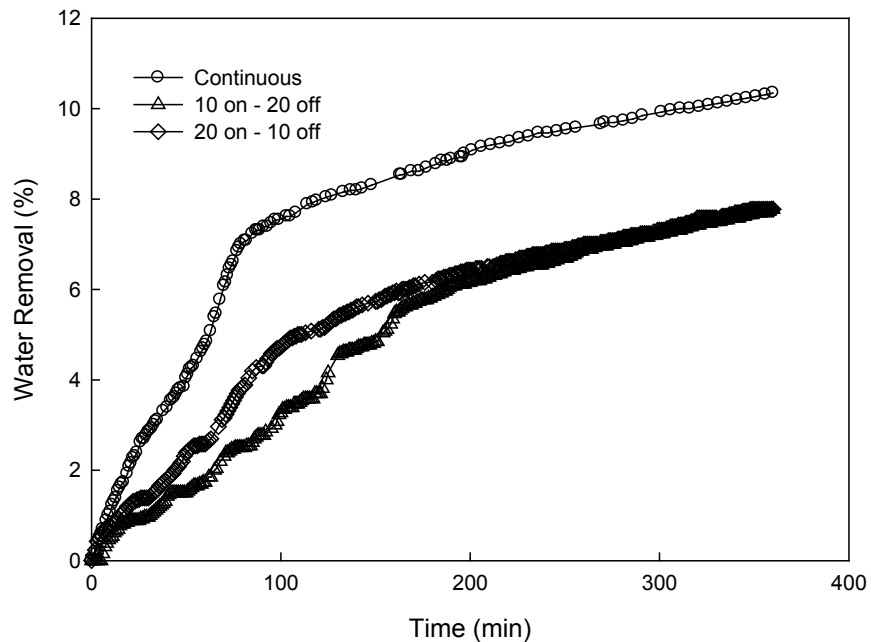

Figure 5: Percentage of water removal for OMW at different power consumption under constant DC voltage and different scenarios. Initial solid concent. $4.4 \mathrm{wt} \%$, voltage $20 \mathrm{~V}$ and bed height, $4 \mathrm{~cm}$

\begin{tabular}{|l|l|l|l|}
\hline $\mathrm{pH}$ & TDS $(\mathrm{mg} / \mathrm{l})$ & $\mathrm{COD}(\mathrm{mg} / \mathrm{l})$ & On \& off time \\
\hline 4.525 & 39300 & 120000 & Original \\
\hline 6.27 & 9300 & 46000 & Continuous \\
\hline 9.9 & 16182 & 69200 & 20 0n \& 10 off \\
\hline 7.68 & 12090 & 69800 & 10 on $\& 20$ off \\
\hline
\end{tabular}

Table 4: Characteristics of water after EOD process under constant voltage and varies power consumption.

to the suspension before the beginning of the experiment with different. Then EOD was conducted for about 5 hours. It was expected that the percentage removal would increase with increasing the concentration of the alum, since alume can agglomerate the particles together and this in turns improve the dewatering process. This is clearly demonstrated in Figure 6 after 200 min of the experiment. It was also noticed (data not shown) that the increase in alum concentration decreases the energy of dewatering. This would signify the importance of adding coagulant to such this process.

\section{Effect of electrolyte}

The ionic strength, $I$, of a solution is a function of the concentration of all ions present in a solution. It can be calculated by the expression:

$$
I_{c}=\frac{1}{2} \sum_{B=1}^{n} c_{B} z_{B}^{2}
$$

where $c_{\mathrm{B}}$ is the molar concentration of ion $\mathrm{B}\left(\mathrm{mol} \mathrm{dm}^{-3}\right), z_{\mathrm{B}}$ is the charge number of that ion, and the sum is taken over all ions in the solution. Increasing the concentration or valence of the counter ions compresses the double layer and increases the electrical potential gradient. The use of electrolyte has also been identified as a means of improving the kinetics and power consumption of electro-osmosis dewatering [24]. Sludge with high conductivity may reduce the rate of electro-osmosis dewatering; hence, there is a limit for electrolyte's concentration to be effective. Three types of electrolytes have been tested in this, namely $\mathrm{CaCl}_{2}, \mathrm{NaCl}$ and $\mathrm{HCl}$. In this case, solutions of different electrolytes at certain concentrations were prepared and been added to the suspension, before the beginning of the experiment, at different amounts to result in different concentrations in the final suspensions. Then EOD was then conducted for about 5 hours. 
Constant voltage tests were implemented with bed height fixed at $4 \mathrm{~cm}$. The results for EOD of OMW using different concentrations of $\mathrm{CaCl}_{2}, \mathrm{NaCl}$ and $\mathrm{HCl}$ are shown in Figure 7A, B and C, respectively. It was expected that the percentage removal would increase with increasing the concentration of the electrolyte; this is due to the increase in the ionic strength of the solution which in turns improves the dewatering process. However, the results did not show such trend for all electrolyte concentrations. This could be due to that high concentration of the electrolyte that results in a reverse effect on the dewatering process. In the case of $\mathrm{CaCl}_{2}$, the low concentrations lead to negative effect on EOD and an optimum concentration of $0.11-\mathrm{wt} \% \mathrm{CaCl}_{2}$ resulted in highest amount of water removal (Table 5). In the case of $\mathrm{NaCl}$, the optimum concentration for enhancement of EOD was $0.12-w t \% ; \mathrm{NaCl}$ concentrations higher or lower than this value did not effect the water removal significantly. Low concentration of $\mathrm{HCl}$ depress the EOD of ME, 0.035 -wt $\%$, while higher concentrations, 0.07 and 0.14 -wt $\%$, have almost same behavior as that without electrolyte (Figure 7C). In general, for all types of electrolytes, it was noticed that the current decreases with time and that energy of dewatering decreases at the start-up of the experiments and then reaches its smallest values when percent of water removal was $5 \%$. It can be concluded that the most effective electrolyte on this EOD process was 0.12 -wt $\% \mathrm{NaCl}$ which resulted in the highest percentage of water removal, and lowest amount energy of dewatering. One drawback of using such chloride electrolytes is the corrosion of the electrodes and hence electro-coagulation rather than electro-osmotic dewatering. However, the concentrations of the electrolytes used in this work were very low that electro-coagulation was not noticed during the course of the experiments.

\section{Conclusion}

Olive mill effluent wastewater is characterized by acidity ( $\mathrm{pH} 4.52$ ),

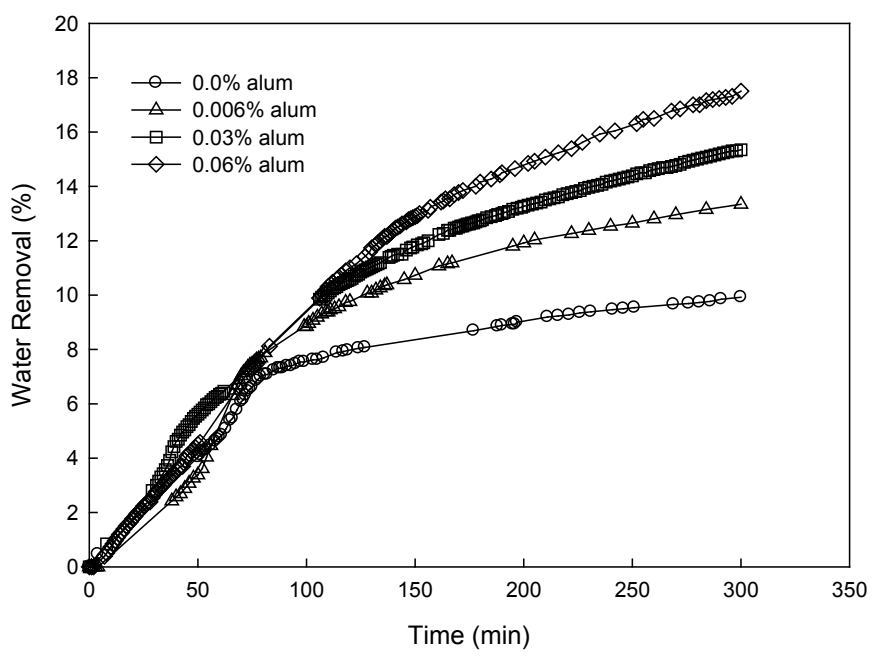

Figure 6: Percentage of water removal for $\mathrm{OMW}$ at different alum concentrationes under constant DC voltage, initial solid concentcentration 5 wt $\%$, voltage $20 \mathrm{~V}$ and bed height $4 \mathrm{~cm}$.

\begin{tabular}{|l|l|l|l|l|}
\hline lonic strength $(\mathrm{M})$ & $\mathrm{pH}$ & $\mathrm{TDS}(\mathrm{mg} / \mathrm{l})$ & $\mathrm{COD}(\mathrm{mg} / \mathrm{l})$ & $\mathrm{CaCl}_{2}$ concentration \\
\hline 0 & 4.525 & 39300 & 120000 & Original \\
\hline 0.0057 & 10.97 & 11098 & 83300 & $0.055 \mathrm{wt} \%$ \\
\hline 0.0114 & 10.74 & 9548 & 49400 & $0.11 \mathrm{wt} \%$ \\
\hline 0.0228 & 8.72 & 9486 & 33000 & $0.22 \mathrm{wt} \%$ \\
\hline
\end{tabular}

Table 5: Characteristics of water after EOD process under constant voltage and different $\mathrm{CaCl}_{2}$ concentrations.
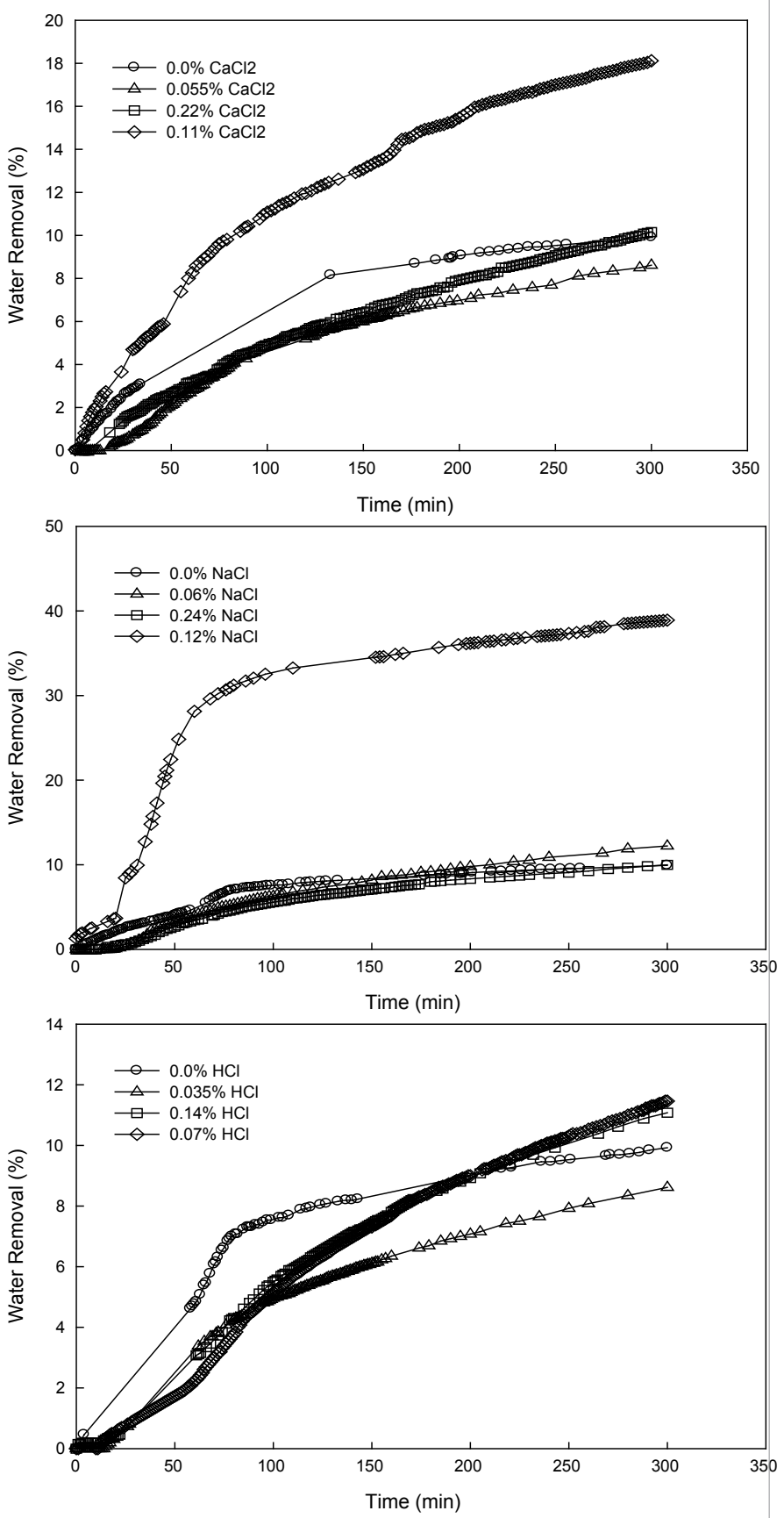

Figure 7: Percentage of water removed for OMW using different concentrations of $\mathrm{CaCl}_{2}(\mathrm{~A}), \mathrm{NaCl}(\mathrm{B})$ and $\mathrm{HCl}(\mathrm{C})$ under constant $\mathrm{DC}$ voltage, initial solid content $4.4 \mathrm{wt} \%$, and a voltage of $20 \mathrm{~V}$.

high organic content (120000 mg COD/l), and large amount of total solid (4.4-wt\% solid content). It was found that the dewatering rate increases with the increase in the applied voltage. At constant applied voltage, the removal rate increases with time whereas current decreases with time. Instantaneous energy of dewatering decreases with time. At constant applied current, the removal rate increases with time whereas voltage increases with time. The on/off test, although saves energy, but did not perform better in the term of percentage water removal compared to that of the continuous process, without on/off test. Increasing the initial bed height decreases the dewatering rate, 
Citation: Al-Asheh S, Juma R, Banat F, Al-Zou'bi A, Al-Qutaish N (2011) Treatment of Olive-Mills effluent using Electro-osmosis Dewatering. Hydrol Current Res 2:113. doi:10.4172/2157-7587.1000113

the percentage of removal water and energy of dewatering. Addition of alum or electrolyte at certain concentration enhanced the removal rate. Sodium chloride is the most effective electrolyte in EOD process. The effluent of the EOD process still contains large degree of COD and further treatment of such effluent using other wastewater treatment techniques is needed.

\section{References}

1. Hayek B, Mosa M, Halasah N (1996) An Experimental method for treatment of olive mills wastewater utilizing up flow anaerobic sludge blanket (UASB) reactor. Presented at Jordan Chemical Engineering Conference II Jordan September 2-4 pp 64-81

2. Boari G, Mancini I, Trulli E (1993) Anaerobic Digestion of Olive Oil Mill Effluent Pretreated and Stored in Municipal Solid Waste Sanitary Landfills. Water Sci Technol 28: 27-34.

3. Chen G, Mujumdar AS (2002) Application of Electrical Fields in Dewatering and Drying. Developments in Chemical Engineering and Mineral Processing 10: $429-442$

4. Khalid AF, Al-Zou'bi (2003) Electro-osmosis of Tomato Paste Suspension. MSc Thesis Jordan University of Science and Technology.

5. Fa-De Li , Li X, Sotome I, Isobe S (2007) Effect of different electric fields on temperature rise, energy efficiency ratio, and solids content during electroosmotic dewatering of tofu residue (okara).Rep. Nat'l Food Res Inst 71: 15-26.

6. Jumah R, Al-Asheh S, Banat F, Al-Zou'bi K (2005) Electro-osmotic Dewatering of Tomato Paste Suspension Under AC Electric Field. Drying Technology 23: 1465-1475.

7. Jumah R, Al-Asheh S, Banat F, Al-Zoubi K (2007) Influence of salt, starch and $\mathrm{pH}$ on the electroosmosis dewatering of tomato paste suspension. $\mathrm{J}$ Food Agriculture \& Environment 5: 34-38.

8. Al-Asheh S, Jumah R, Banat F, Al-Zou'bi K (2004) Direct Current Electroosmosis Dewatering of Tomato Paste Suspension. Trans I ChemE, Part C Food and Bioproducts Processing 82:193-200.

9. Saveyn H, Curvers D, Pel L, de Bondt P, Van der Meeren P (2006) In situ determination of solidosity profiles during activated sludge electrodewatering. Water Res 40: 2135-2142

10. Zhou Y, Liang Z, Wang Y (2008) Decolorization and COD removal of secondary yeast wastewater effluents by coagulation using aluminum sulfate. Desalination 225: 301-311.

11. Yang L, Nakhla G, Bassi A (2005) Electro-kinetic dewatering of oily sludges. J Hazard Mater 125: 130-140.

12. Reddy KR, Urbanek A, Khodadoust AP (2006) Electroosmotic dewatering of dredged sediments: Bench-scale investigation. J Environ Manage 78: 200-208.

13. Asadi A, Huat BBK, Shariatmadari N (2009) Keeping Electrokinetic Phenomena in Tropical Peat into Perspective. European Journal of Scientific Research 29: 281-288.
14. Lockhart NC (1983) Electro-osmotic dewatering of clays. II. Influence of Salt, Acid, and Flocculants. Colloids Surf 6 : 239-251.

15. Ju S, Weber ME, Mujumdar A (1991) Electro-osmotic dewatering of bentonite suspensions. Separations Technology 1: 214-221.

16. Rabi HR (1992) Continuous and Interrupted Electro-osmotic Dewatering of Clay suspension. MSc. Thesis McGill University Montreal Quebec

17. Yoshida H, Kitajyo K, Nakayama M (1999) Electroosmot1c Dewatering Under A. C. Electric Field With Periodic Reversals Of Electrode Polarity. Drying Technology 17: 539-554

18. Chen H, Mujumdar AS, Ragbaran GSV (1996) Laboratory Experiments on Electro-osmotic Dewatering of Vegetable Sludge and Mine Tailings .Drying Technology, 14: 2435-2445.

19. Zhou J, Zheng, L, Peng S, Fuxing D (2001) Water Removal From Sludge In A Horizontal Electric Field. Drying Technology 19: 627-638.

20. Tezcan U, Ugur S, Koparal AS, Ogutveren UB (2006) Electro-coagulation of olive mill wastewaters. Separation and Purification Technology $52: 136-141$.

21. Iwata M, Jami MS (2010) Analysis of Combined Electro-osmotic Dewatering and Mechanical Expression Operation for Enhancement of Dewatering .Drying Technology 28: 881-889.

22. Hsu J, Su A, Mujumdar AS, Lee D (2010) Unified Analysis of Dewatering and Drying of Sludge Cake. Drying Technology 28: 877-880.

23. Xian-shu, D, Xiao-jie H, Su-ling Y, Wei-peng R, Zhi-zhong W (2009) Procedia Earth and Planetary Science $1: 685-693$.

24. Curvers D, Usher S, Kilcullenb A, Scales P, Saveyn H, et al. (2009) The influence of ionic strength and osmotic pressure on the dewatering behaviou of sewage sludge. Chem Eng Sci 64: 2448-2454.

25. Yang Z, Lee D (2010) Structure Evolution of Wastewater Sludge during Electroosmotic Dewatering .Drying Technology 28: 890-900.

26. Riffaldi R, Minzi R, Saviozzi A, Vanni G, Scanicnozz A (1993) Effect of the disposal of sludge from olive processing on some soil characteristics: Laboratory experiments. Water Air Soil Pollut. 69: 257-264.

27. Clesceri LS, Greenberg AE, EatonA.D (1992) Standard Methods for the Examination of Water and Wastewater. 18th edition American Public Health Association Washington DC USA.

28. Watanabe S, Yamada Y, Hobo Y, Hayashi N, Sumi T, et al.(2001) A new method of analysing electro-osmosis using FET models. J Electrostat 50-51: 455-462.

29. Krishna R, Reddy R, Urbanek A, Khodadoust AP (2006) Electroosmotic dewatering of dredged sediments: Bench-scale investigation Journal of Environmental Management 78 200-208.

30. Han SJ, Kim SS, Kim B (2004) Electroosmosis and pore pressure development characteristics in lead contaminated soil during electrokinetic remediation. Geosciences Journal 8: 85-93.

31. Vijh AK (2002) Electro-osmotic Dewatering by A "New" Method Using a "Gate" Electrode: Field Effect Transistor (Fet) Model or Simply a Multistage Dewatering?. Drying Technology $20: 705-710$. 